\title{
Ergonomic Assessment of Street Warning Signs for the Visually Impaired in Metro Manila
}

\author{
Stephanie L. Aganad (slaganad@up.edu.ph) ${ }^{1}$, Kirstie Faye A. Tabanda (katabanda@up.edu.ph) ${ }^{1}$, \\ Amiel Joyce R. Bellen (arbellen1@up.edu.ph) ${ }^{1}$, Aenna Mae A. Magpantay \\ (aamagpantay2@up.edu.ph) ${ }^{1}$, Benette P.Custodio (bpcustodio@up.edu.ph)1
}

${ }^{1}$ Department of Industrial Engineering and Operations Research, University of the Philippines, Diliman, Quezon City, Philippines

\begin{abstract}
The Philippine Magna Carta for Disabled Persons (RA 7277) states that persons with disabilities (PWDs) should be granted the same rights and privileges as other people and should be able to live as freely and independently as possible. Based on the 2011 estimated Philippine population of 102 million and the 2002 blindness prevalence of $0.58 \%$ and visual impairment prevalence of 2.04\%, there are approximately 592,000 blind people and 2 million people with moderate or severe visual impairment. Therefore, there is a need to assess whether the streets of Metro Manila are safe for the visually impaired (VI) to navigate. Twenty-seven (27) visually impaired commuters were interviewed to establish the inconveniences they encounter when travelling. Blindfold walk was carried out to simulate and experience these inconveniences. Standard measurements of the street components, and guidelines on street warning signs in the Philippines and other countries that cater to the VI's were gathered. Two locations, Marikina and Bonifacio Global City (BGC), known to have the most pedestrian and PWD-friendly street conditions in the Philippines were chosen for the assessment. Several street components in both locations were measured then compared with standard measurements. Results of the interviews show that 17 out of the 27 (62.96\%) interviewees are capable of navigating the streets on their own while the rest could not travel without a personal guide. The most common problems encountered by the VI's while navigating the streets include (1) parked cars that take up and minimize the space for walking, (2) being given wrong directions, (3) fast cars that have no regard for pedestrians, (4) narrow and crowded sidewalks, and (5) uncovered manholes and pits. Blindfold simulation identified problems in finding the gutter or the lack thereof, identifying obstructions, and crossing the streets. Out of the 52 sample measurements in Marikina, $61.54 \%$ conforms to the standard sidewalk width, $65.38 \%$ conforms to the standard curb height, and $73.08 \%$ conforms to the standard pedestrian crossing width. Out of the 21 sample measurements in BGC, $80.95 \%$ conforms to the standard sidewalk width, $80.95 \%$ conforms to the standard curb height, and $57.14 \%$ conforms to the standard pedestrian crossing width. Results show that Marikina and Bonifacio Global City exhibit consistency in the implementing standard measurements for sidewalks, pedestrian crossings, curb heights, and pole distances. However, the streets lack pedestrian warning signals.
\end{abstract}

Keywords: Ergonomic assessment, Street warning signs, Visually impaired, ESK-JES Joint Session

\section{Introduction}

The goal of ergonomics is to fit the tasks and machines to every man, including the minorities. Among the minorities are the Persons with Disabilities (PWDs) who, according to Republic Act 7277, should be allowed the same rights as other people to be able to live as freely and independently as possible.

Based on the 2011 estimated Philippine population of
102 million and the 2002 blindness prevalence of $0.58 \%$ and visual impairment prevalence of $2.04 \%$, there are now approximately 592,000 blind people in the country and 2 million people with moderate or severe visual impairment (Department of Health, n.d.).

Therefore, there is a need to assess whether the streets of Metro Manila are safe for the visually impaired (VI) to navigate. This study aims to identify problems encountered by VIs in their travel in the local streets, and assess how VI-friendly the locations are. 
VIs are currently able to navigate the streets through the use of canes, guide dogs, personal aid (Harkey et al., 2007) and street-integrated facilities like ramps, pushbuttons, handrails, and tactile surface indicators. In the Philippines, certain measures were installed to cater to the needs of the visually impaired. In 2013, Makati developed a PWD-friendly pedestrian crossing. While in 2016, braille tiles were built around Marikina Sports Center (Alquitran, 2014).

Individuals who are blind or visually impaired often rely on specific street components to roam around unfamiliar areas. In identifying their location on the street, VIs use cues such as sidewalk gutters, curbs, intersecting sidewalks, ramps, truncated domes, sound of traffic, and intersection geometry (i.e. sidewalk width, curb radius). Additionally, VIs should also be able to analyze the traffic control system and identify the location of pushbuttons and tactile arrows to determine when to cross the street. It is also important to consider the width of the pedestrian crosswalk for the proper alignment of path so as not to veer away from the designated lane (Harkey et al., 2007). These street components must comply with standard design requirements which take into consideration the needs of the visually impaired.

Whereas a person without disability is able to comfortably walk along a $70 \mathrm{~cm}$-wide sidewalk (Mace, n.d.), VIs need a relatively larger width to be able to travel with their cane, guide dog, or personal aid. Table 1 shows the standard sidewalk dimensions for VIs developed by Ronald Mace, Founder and Program Director of the Center of Universal Design at the North Carolina State University.

Standards in the Philippines set by the Department of Public Works and Highways agree with the international standards given in the table. By Batas Pambansa Blg. 344 or the Accessibility Law, busy sidewalks should have a minimum dimension of $\mathbf{1 5 0} \mathbf{~} \mathbf{~ m}$ for PWDs to be able to travel (Ebdane Jr., 2009).

Moreover, it is recommended by the New Zealand Transport Agency that pedestrian crosswalks have a width of $250 \mathbf{~ c m}$ (minimum of $200 \mathrm{~cm}$ ) for VIs to safely cross the streets without risk of walking off the course (New Zealand Transport Agency, 2015). Curb height should range from 6 to $22.5 \mathrm{~cm}$ for the ramp elevation to be distinguishable from the road (Axelson et al., 1999). For Accessible Pedestrian Signals the optimal location should be between $\mathbf{1 . 5}$ feet and $\mathbf{1 0}$ feet from the edge of the curb, shoulder, or pavement and each of them should be at least $\mathbf{1 0}$ feet away from each other.
Pushbuttons should be located less than 5 feet from the edge of the pedestrian crossing (Harkey et al., 2007).

Table 1. Recommended sidewalk widths

\begin{tabular}{c|c}
\hline PWD in Consideration & $\begin{array}{c}\text { Recommended } \\
\text { Measurement }\end{array}$ \\
\hline Person with a walking stick & $75 \mathrm{~cm}$ \\
\hline Person with crutches or walking frame & $90 \mathrm{~cm}$ \\
\hline $\begin{array}{c}\text { Blind person with long cane or guide } \\
\text { dog }\end{array}$ & $110 \mathrm{~cm}$ \\
\hline $\begin{array}{c}\text { Visually impaired guided by another } \\
\text { person }\end{array}$ & $120 \mathrm{~cm}$ \\
\hline Wheelchair user with another person & $150 \mathrm{~cm}$ \\
\hline
\end{tabular}

Accessible Pedestrian Signals (APS) should produce sound not higher than 2-5dBA above ambient sound. Other countries like Japan use a cuckoo or chirp sound for this purpose. Tactile arrows that are used point where the pedestrian crossing is should be properly aligned and would vibrate when it is time to cross (Harkey et al., 2007).

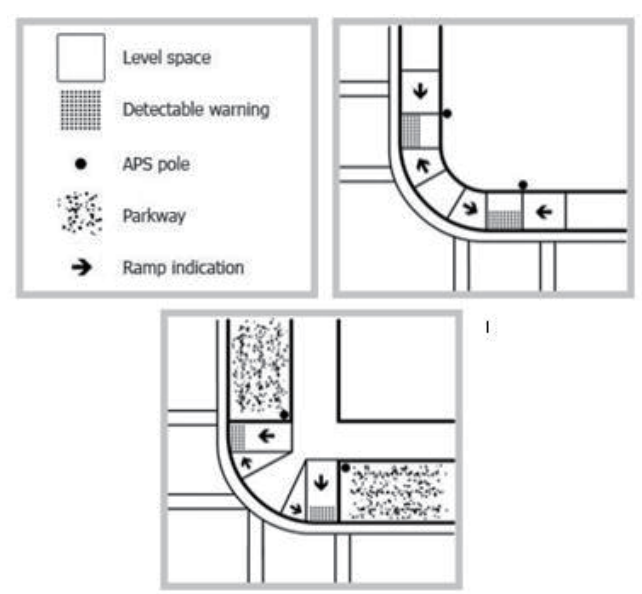

Figure 1. Optimal APS location as recommended by Harkey et.al.

\section{Method}

Twenty-seven (27) visually impaired commuters were interviewed to establish the inconveniences they encounter when travelling. Interviewees were from Munting Pamayanan ng May Kapansanan, Bgy. Escopa, Quezon City, DSWD National Vocational Rehabilitation Center, 
Bgy. Escopa, Quezon City, and BM Dorm House, Manila Blind Church, Bgy. Marilag, Quezon City. Blindfold walk was carried out to simulate and experience these inconveniences. Results of the interviews and blindfold walk were used to identify the critical components of a VI-Friendly Street.

To assess whether the local streets were designed to be VI-friendly, standard measurements of the street components, and guidelines on street warning signs in the Philippines and other countries that caters to the VI's were gathered. Available standards include recommended measurements of sidewalk dimensions, curb height, pedestrian crosswalks width, and distance between poles. Standard guidelines include presence of handrails, pushbuttons, truncated domes, short Pedestrian Posts, and ramps.

Two locations, Marikina and Bonifacio Global City (BGC), known to have the most pedestrian and PWD-friendly street conditions in the Philippines were chosen for the assessment. Several street components in both locations were measured then compared with standard measurements. To determine whether these locations are VI-friendly or not, the number of nonconformities, defined as the absence of the critical street components and noncompliance to the standard measurements, were counted and assessed.

\section{Results}

The results of the interviews show that 17 out of the 27 $(62.96 \%)$ interviewees are capable of navigating the streets on their own while the rest could not travel without a personal guide. All 27 interviewees are aware and make use of handrails, $63 \%$ of them utilize and are familiar with tactiles, and $27 \%$ of them are knowledgeable of the pushbuttons for pedestrian crossing. Their suggestions for better navigation of the streets include having a sidewalk specifically for people with disability, alarms and warning sounds for traffic lights, Braille signs and street names, better implementation of traffic laws, less crowded sidewalks, and properly covered manholes and pits. The most common problems encountered by the VI's while navigating the streets include (1) parked cars that take up and minimize the space for walking, (2) being given wrong directions, (3) fast cars that have no regard for pedestrians,
(4) narrow and crowded sidewalks, and (5) uncovered manholes and pits.

Blindfold simulation identified problems in finding the gutter or the lack thereof, identifying obstructions, and crossing the streets. These are similar to those discussed by the VI's during the interview. Therefore, critical street components to be assessed for the chosen locations include sidewalk width, curb height, pedestrian crossing width, and pedestrian crossing indicator.

The streets in Marikina City and Bonifacio Global City covered by the assessment are found in Figures 2 and 3 . Looking at the ramps of the two locations, most ramps in Marikina City have tactile pavements at its end. Only the main and wide roads have assigned traffic enforcers at the pedestrian crossing to help the people cross. Electric posts and cars along the parkway were the primary obstructions on the sidewalks. Additionally, the measurements have wide ranges and deviation. Table 2 shows the comparison of the measurement and the standards.

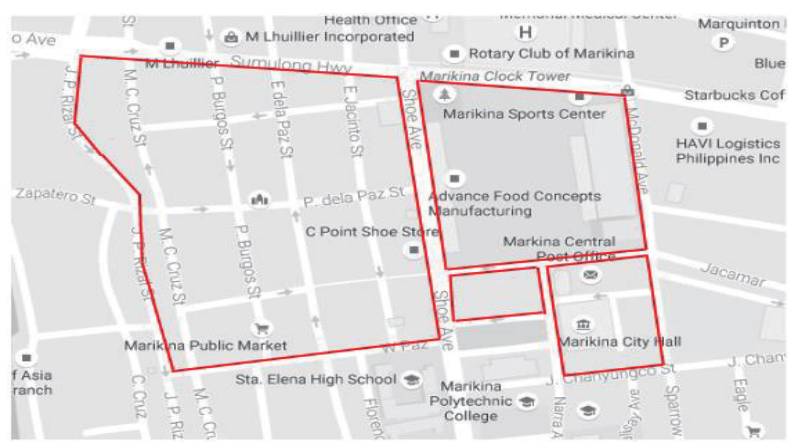

Figure 2. Traced Map of Marikina City

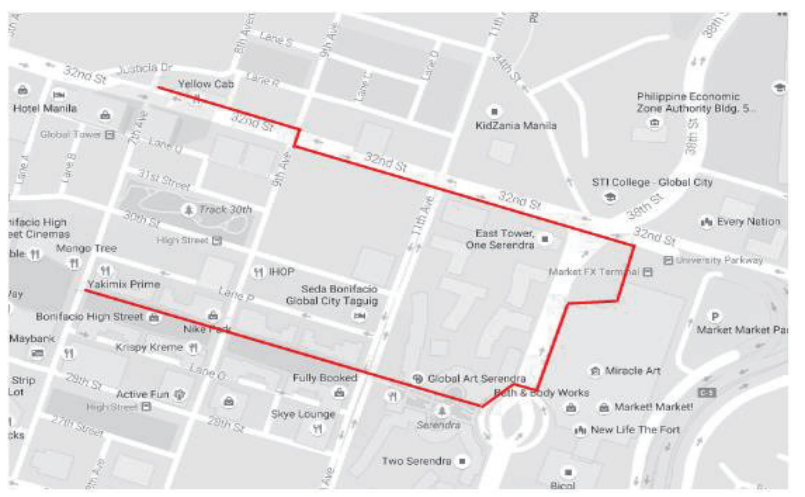

Figure 3. Traced Map of Bonifacio Global City

BGC had ramps and pushbuttons at every corner and trees planted every $400 \mathrm{~cm}$ along the sidewalks. These sidewalks follow a ribbon sidewalk design. However, the pushbuttons do not work. There are no traffic enforcers 
along the main roads since they use timed pedestrian stoplight.

Neither of the observed locations had special street indicators.

Table 2. Component Measurements in Marikina and BGC

\begin{tabular}{|c|c|c|c|}
\hline Components & $\begin{array}{c}\text { Marikina } \\
\text { (cm) }\end{array}$ & $\begin{array}{l}\text { BGC } \\
(\mathrm{cm})\end{array}$ & $\begin{array}{l}\text { Standard } \\
\text { (cm) }\end{array}$ \\
\hline Sidewalk Width & 286.40 & 543.29 & \multirow{4}{*}{$(75,150)$} \\
\hline Range & $(85,592.5)$ & $(354,756)$ & \\
\hline StDev & 152.26 & 124.37 & \\
\hline Sample Size & 29 & 17 & \\
\hline Curb Height & 15.94 & 18.75 & \multirow[t]{4}{*}{$(6,22.5)$} \\
\hline Range & $(0,27)$ & $(16,24)$ & \\
\hline StDev & 4.45 & 1.99 & \\
\hline Sample Size & 32 & 18 & \\
\hline Pole Distance & 87.17 & 75.92 & \multirow{4}{*}{$(45.72,304.8)$} \\
\hline Range & $(27,172)$ & $(56,96)$ & \\
\hline StDev & 37.14 & 13.11 & \\
\hline Sample Size & 32 & 13 & \\
\hline PedXing Width & 524.90 & 442.92 & \multirow[t]{4}{*}{250} \\
\hline Range & $(343,859)$ & $(395,640)$ & \\
\hline StDev & 115.62 & 82.38 & \\
\hline Sample Size & 34 & 12 & \\
\hline
\end{tabular}

Out of the 52 sample measurements in Marikina, $61.54 \%$ conforms to the standard sidewalk width, $65.38 \%$ conforms to the standard curb height, and $73.08 \%$ conforms to the standard pedestrian crossing width. Out of the 21 sample measurements in BGC, $80.95 \%$ conforms to the standard sidewalk width, $80.95 \%$ conforms to the standard curb height, and $57.14 \%$ conforms to the standard pedestrian crossing width.

\section{Conclusion}

The city of Marikina and Bonifacio Global City both observe PWD-friendly standards and safety measures. Both exhibit consistencies in implementing standard measurements for sidewalks, pedestrian crossings, curb heights, and pole distances, especially in BGC. The street components conform to the standard measurements, indicating that there is an ample amount of space provided for pedestrians. Both locations have installed handrails, short pedestrian posts, and truncated domes which aid in way finding and hazard detection. However, streets lack warning signs for crosswalks which is a crucial component as deemed from the interviews. BGC have pushbuttons at every corner to aid in crossing but they do not function.

In conclusion, both cities observe standard measurements for critical street components but lack pedestrian warning signs thus, not qualifying as VI-friendly cities. Because these cities are regarded as two of the most pedestrian and PWD-friendly cities in Metro Manila, it can be said that Metro Manila is not yet VI-friendly.

\section{References}

Department of Health, Prevention of Blindness Program, Department of Health website, n.d.

S. Crisostomo, Visually Impaired Pinoys to Hit over 2 M this year - study, The Philippine Star, 2014.

D. L. Harkey, D. L. Carter, J. M. Barlow, and B. Bentzen, Accessible Pedestrian Signals: A Guide to Best Practices. National Cooperative Highway Research Program. North Carolina, 2007.

N. Alquitran, Marikina puts up Braille tiles along sidewalks. The Philippine Star, 2014.

R. Mace, Accessible Street Design. The City Vancouver Engineering Services, n. d.

H. E. Ebdane Jr., Enforcement of the Accessibility Law (BP 344) Along National Roads, Department Order No. 37. Department of Public Works and Highways. Manila, 2009.

NZ Transport Agency, RTS 14 - Guidelines for Facilities for Blind and Vision Impaired Pedestrians. Road and Traffic Standard Series, 3rd ed. Wellington, 2015.

Beneficial Designs Inc., P. W. Axelson, D. A. Chesney, D. V. Galvan, J. B. Kirschbaum, P. E. Longmuir, C. Lyons, and K. M. Wong, "Chapter 4: Sidewalk Design Guidelines and Existing Practices" in Designing Sidewalks and Trails for Access. U. S. Department of Transportation. Washington D.C.., 1999.

T. Perkins, Chesterfield MP on blindfold walk to raise awareness of 'street clutter'. Chesterfield, 2014

D. Burtt, Road Safety Audit Tool for Pedestrians who are Vision Impaired. Vision Australia (Victoria). Melbourne, 2014

L. Rodegerdts, J. Bansen, C. Tiesler, J. Knudsen, E. Myers, M. Johnson, M. Moule, B. Persaud, C. Lyon, S. Hallmark, H. Isebrands, R. B. Crown, B. Guichet, and A. O'Brien, "2.3.2 Pedestrians with Disabilities. Transportation Research Board" in Roundabouts - An Informational Guide (2nd Edition): (NCHRP Report 672). Transportation Research Board, 2010.

New York City Department of Transportation, "2.0 Geometry" in Street Design Manual, 2nd ed. Vanguard Direct: New York, 2015. 